\title{
Properties of the organization of memory for people: Evidence from dream reports
}

\author{
RICHARD SCHWEICKERT \\ Purdue University, West Lafayette, Indiana
}

\begin{abstract}
Steyvers and Tenenbaum (2005) showed that semantic networks for words have three organizational properties: short average path lengths, high clustering, and power law degree distribution. If these are general properties of memory organization, they would apply to memory for other complex material, including people and relations between them. In addition, if during dreaming, characters are generated via knowledge in the dreamer's memory, the three properties would be found in a relational network of characters in dreams. In dream reports from three individuals, two characters in the same dream were considered affiliated. Resulting social networks have the three properties, with the power law holding when low degrees are omitted. One network with a treelike outline is different from the other two. Results suggest associative memory has the three properties, and demonstrate that dream reports are a potentially valuable source for information about social networks.
\end{abstract}

\begin{abstract}
Although the knowledge of people and their relations forms an important part of each person's memory, it is not as well researched as, say, semantic memory for words. A major way of obtaining information about social networks is asking respondents to remember the people they interact with (Wasserman \& Faust, 1994). When results can be compared with observations, many inaccuracies are found (e.g., Brewer, 2000; Killworth \& Bernard, 1976; Kumbasar, Romney, \& Batchelder, 1994). Supplemental information would be valuable.
\end{abstract}

An alternative source is dream reports, but would they be useful? The peculiar nature of the events that occur in dreams raises doubts that such events are systematic. On the other hand, dreams are concerned with people and issues of importance to the dreamer (e.g., Hall \& Nordby, 1972). Further, McNamara, McLaren, Smith, Brown, and Stickgold (2005) conjecture that dreaming is specialized for simulation of social interactions.

A second question is whether information about memory can be found in dreams. Memory appears relatively functional during dreaming (Foulkes, 1985), consistent with the finding of activity during REM sleep in parahippocampal gyri and contiguous portions of the hippocampus (Braun et al., 1998). Dreams rarely replay incidents from waking life (Fosse, Fosse, Hobson, \& Stickgold, 2003), so episodic memory is not directly relevant. But relations between elements in dreams often correspond to those in waking life, so associative memory is functioning, at least partly.

By comparison, the effects of external stimuli during dreaming are small and unsystematic (Arkin \& Antrobus, 1991; Domhoff, 2003; Foulkes, 1985). This is consistent with the finding that activity in primary visual cortex is attenuated during REM sleep (Braun et al., 1998). Because there is little external input, if there are regularities in dreams they arise largely through the dreamer's memory (Foulkes, 1985; Grenier et al., 2005). The purpose here is to see whether something systematic about social networks can be extracted from dream reports, and if so, what form it takes.

\section{Network Forms}

In social networks, vertices represent actors (typically, people), and a line (an edge) joins two vertices to represent a relation between the corresponding actors. Given the unusual narratives in dreams, deciding whether two characters have a relationship could be difficult. A well established procedure in social network analysis is to consider two people related if they appear at an event together (Wasserman \& Faust, 1994). A social network constructed this way is called an affiliation network. Here, two characters are considered affiliated if they are in a dream together.

Of the many forms social networks take, let us consider a few that are plausible for dreams. Occasional bizarre events and abrupt transitions give dreams a somewhat random appearance. A long-standing hypothesis is that dreams originate from more or less random physiological signals, although their further processing may not be random (Hobson \& McCarley, 1977). A recent stronger hypothesis (Tsonis \& Tsonis, 2004) is that associations in REM sleep follow a random network model of Watts and Strogatz (1998). In another type of random network (Newman, Watts, \& Strogatz, 2002), edges join vertices at random, independently. However, such random networks are rendered unlikely by the analysis of an individual's dream (Domhoff, 2003, p. 104), in which two important characters, the dreamer's husband and her minister,

R. Schweickert, swike@psych.purdue.edu 
occurred together significantly less often than predicted by statistical independence.

Another possibility is a treelike structure. In a tree, there is at most one path from one vertex to another. Treelike structures are rare for social networks, but a recent example is a network of high school students, in which two people were joined by an edge if they reported a romantic or sexual relationship (Bearman, Moody, \& Stovel, 2004). The network is similar to a tree, because it contains few paths that start and end at the same vertex (closed paths). The authors point out that such structure does not arise by chance; something must inhibit the formation of closed paths. For their network, they observe that people do not date the former (or current) partner of their former (or current) partner. A treelike structure is a possibility for a social network based on dreams. The nonindependence reported by Domhoff (2003) is of an inhibitory kind, because two individuals occurred together less often than predicted by chance.

Another possibility is a small world network, so called for the short path of mutual acquaintances that often exists between two people (Milgram, 1967). The property is not distinctive, because it also occurs in the random networks mentioned. Many social networks are distinguished from such random networks by high clustering; that is, if a person knows two people, those two people are more likely to know each other than are two people chosen randomly. Small world networks are networks with short paths and high clustering (somewhat loosely defined) (Watts \& Strogatz, 1998). A third property found in many small world networks is as follows: The degree of a person in a social network is the number of people who have a relationship with that person; that is, the degree of a vertex is the number of edges incident with that vertex. A network follows a power law if the probability that a vertex has degree $k$ is proportional to a negative power of $k$ (Barabasi \& Albert, 1999; Johnson, Kotz, \& Kemp, 1992).

Small world properties characterize a variety of structures, including many social networks, the World Wide Web, and connections in the brain (Albert, Jeong, \& Barabasi, 1999; Sporns, Tononi, \& Edelman, 2000; Stephan et al., 2000; Watts \& Strogatz, 1998). Human memory contains a vast network of associations (e.g., Collins \& Loftus, 1975; Rumelhart, Lindsay, \& Norman, 1972), and recently Tsonis and Tsonis (2004) proposed that it is a small world network.

Support for this proposal comes from the recent finding of the three properties in semantic networks for words (Steyvers \& Tenenbaum, 2005). These were constructed from Roget's (1911) Thesaurus, WordNet (Miller, 1990), and word association norms (Nelson, McEvoy, \& Schreiber, 1999). Also, Vitevitch (2005) found the three properties in a network of phonological relations between words (Nusbaum, Pisoni, \& Davis, 1984). English speakers have knowledge in memory of most of the relations represented in these networks. This suggests that the representation of this knowledge in an individual's memory has the properties.

Suppose the three properties are general properties of an individual's memory for relations, not only for words, but for other material with complex relations, including people. Further suppose that characters are generated in dreams in accordance with relations in the dreamer's memory; a relational network of characters in dreams would then have the three properties.

\section{METHOD}

\section{Materials}

Dream reports of three adults were selected from a database (Schneider \& Domhoff, 2005), so each entire series could be coded. At the time of her dream reports - 1992 to 1998-Arlie (names are pseudonyms) was married, with four grown children. At the time of her dream reports - 1999 to 2000-Merri was unmarried, in her 30 s. The Natural Scientist was unmarried and 46 when he wrote his reports in 1939. He wrote another one in 1949.

In the 212 Arlie dream reports, four with ambiguous references to characters were omitted. The ambiguous references my son and my daughter were cleared up after anonymous communication with the dreamer (through a database manager, G. W. Domhoff), explaining that these terms referred to her younger son and younger daughter. Of the 316 Merri reports, at the time of coding, report \#019 was a continuation of \#018, \#021 was a continuation of \#020, \#041 was a copy of \#039, and \#096 was a copy of \#095, yielding a true total of 312 reports. For The Natural Scientist, part of \#097 is probably part of an earlier dream report and was therefore coded with that report (\#095).

\section{Procedure}

The major system for content analysis of dreams, by Hall and Van de Castle (1966; Domhoff, 1996), has a low threshold for coding a character. For example, the appearance of something belonging to a person is sufficient for the person to be coded. The criteria of this system were modified for presence closer to the notion of a social network. In the modified system, a character is a person or an entity that someone in the dream, including the dreamer, could have a social interaction with, or an entity such as a husband taking a role ordinarily taken by a person. The dreamer is a character, but only coded as present if appearing in a different form (e.g., as a character of different gender). Characters include fanciful figures, such as an invisible old lady and her minnow husband.

A character is present in the dream if the dream report directly indicates such presence; or if someone states or implies in the dream, without expressing doubt, that the character is present; or if social interaction is possible between the character and another character, perhaps through the media mentioned, whether or not an interaction has taken place. Characters in a group are ignored unless the number of individuals in the group is known, or individuals are discussed separately. A baby in the process of being born is a character present, but an unborn baby, or one soon to be born, is not. Dying characters are present, but dead bodies are not. Ghosts and animated corpses are characters present.

A report from Arlie follows.

\section{\#199 (9/4/98)}

I am visiting in my hometown. The roads are slippery and it is hard to get around. I want a donut and I find it hard to get to that street. As I am there I am coming out the door when one of the Lewis boys (neighbors) comes to the door. He is wearing an overcoat but I can see he has been cut off at the knees. I want to ask about it but decide to ask my mother instead. After he is gone we are making our way on very slippery streets to the office supply store at the newspaper where I used to work so I can buy an account book and one other item I can't remember. I ask my mother what happened to the Lewis boy and she motions for me to be quiet until we are far enough away so he can't hear us. We get to the back door in the alley and I wake up. I only hear it was something about his grandfather and he got some kind of transplant from the grandfather who is now dead. (187 words) 
Two characters are present, one of the Lewis boys and the dreamer's mother. The grandfather is mentioned, but is not actually present.

Reports give little information about some characters. Here is an example from The Natural Scientist.

\#076 (08/13/39)

Billiard table in living room was being moved. The man on one end, because his hand hold was too high, lifted the slate bed off the base. ( 27 words)

The man in this dream may appear in other dreams, but there is no way to know. He is coded in this dream only. For another coding example, see a preliminary report on the first 100 dreams of Merri (Schweickert, 2007).

\section{RESULTS}

An affiliation social network for each dream series was constructed by representing each character as a vertex and joining two characters with an edge if they were present together in at least one dream. Networks for Arlie and The Natural Scientist are in Figures 1 and 2, respectively. (Merri's network is too dense to illustrate clearly.) In Arlie's network the vertex with the most edges, near the center of the figure, represents her husband. A giant component contains all high-degree vertices. Vertices with a large number of edges tend to be joined to one another by edges. Many small sets of vertices are isolated, representing characters appearing together in a dream but not joined to anyone in the giant component. An isolated single vertex represents a character in a dream alone. (Placement of vertices is for visual clarity, with no significance in itself.) The network for Merri has a similar form. In her network, the character of highest degree is her sister Dora, who, we learn from the Web site, died before the series of dream reports began. The network for The Natural Scientist is different from the other two. The vertex of highest degree, in the center, represents the dreamer's mother. Unlike in the networks of Arlie and Merri, pairs of high-degree characters are not especially likely to be joined by an edge. Away from the center, the giant component has a treelike outline (it cannot be precisely a tree, because when three or more characters are in a dream together they are joined by edges). The treelike form reflects the fact that characters from work rarely occur in The Natural Scientist's dreams with characters from his family, and so on.

The length of the shortest path between each pair of characters was calculated on the basis of the standard procedure of ignoring pairs with no path between them (Newman, 2003). The clustering coefficient for a character $x$ is the proportion of cases in which two characters who are each in a dream with $x$ are in a dream with each other (Watts \& Strogatz, 1998). The clustering coefficient for a network is the average clustering coefficient over characters. Table 1 gives the average shortest path lengths and clustering coefficients (Batagelj \& Mrvar, 1998).

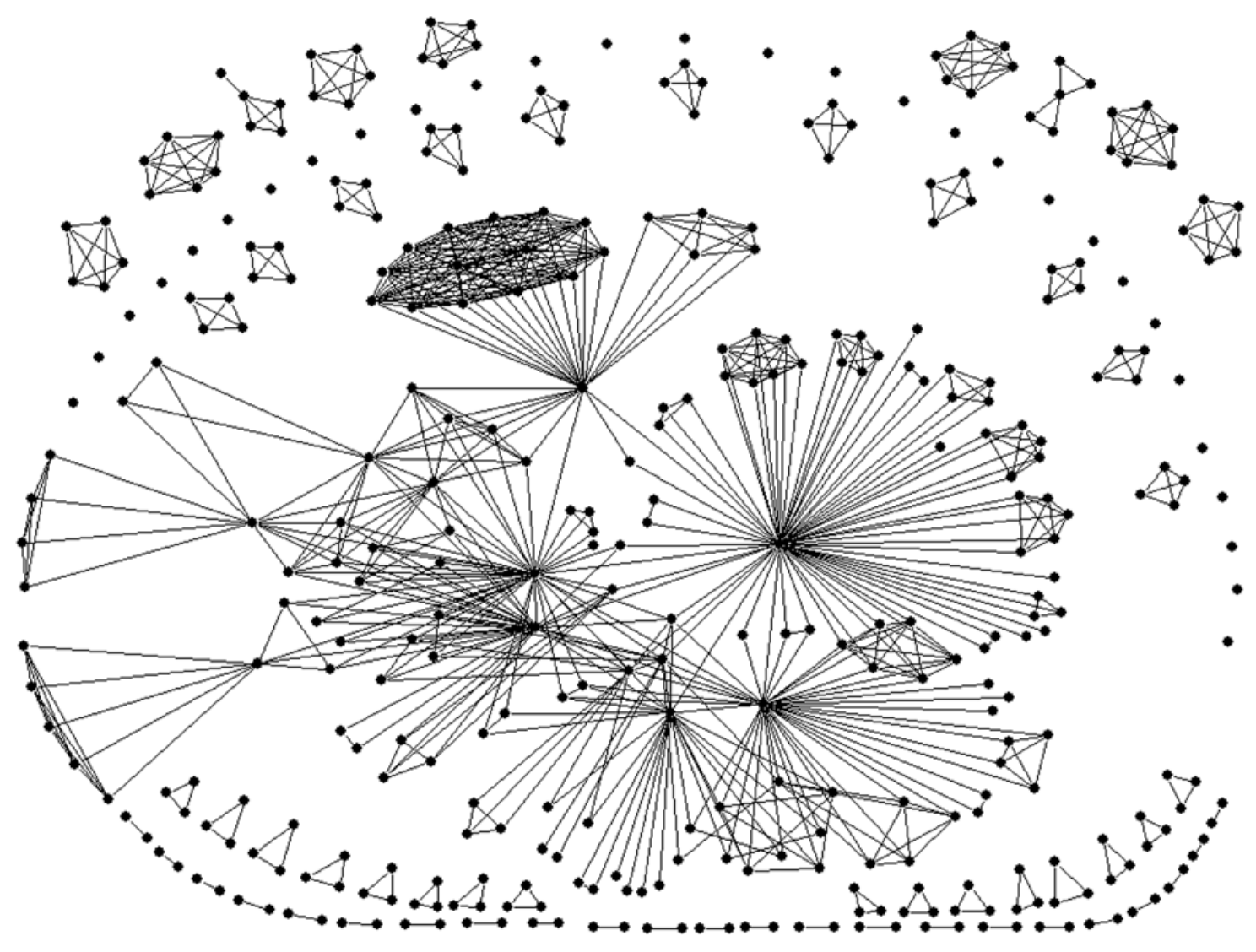

Figure 1. Social network for characters in Arlie's dreams. 


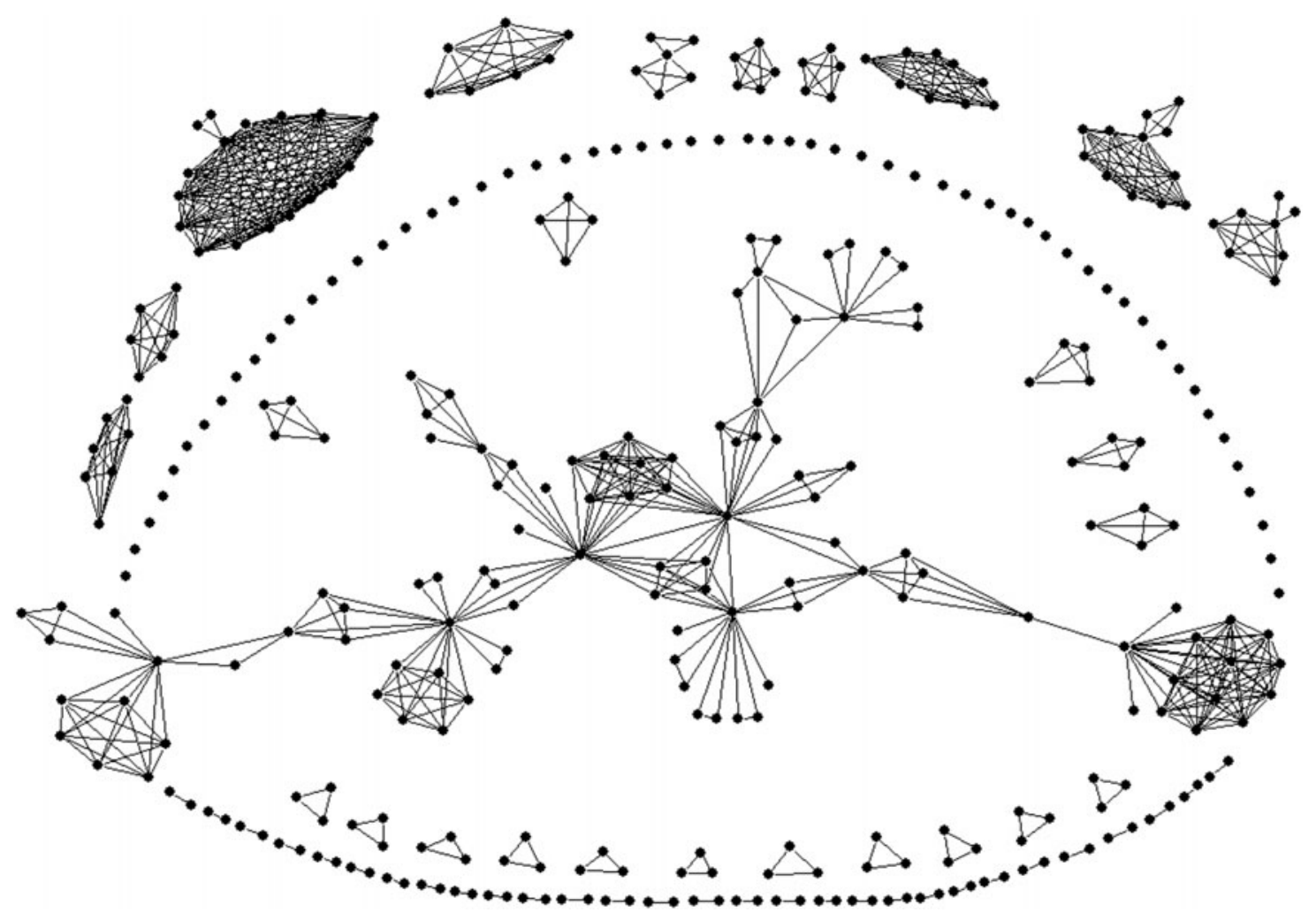

Figure 2. Social network for characters in The Natural Scientist's dreams.

Corresponding values were calculated for the following population of comparable random affiliation networks (Newman et al., 2002). For dreams, there is an observed distribution for the number of characters in a dream. Likewise, for characters, there is an observed distribution for the number of dreams a character is in. In the population of comparable random affiliation networks, the number of characters and the number of dreams are as observed, the number of

Table 1

Properties of Three Dream Social Networks

\begin{tabular}{lccc}
\hline & \multicolumn{3}{c}{ Dreamer } \\
\cline { 2 - 4 } & Arlie & Merri & $\begin{array}{c}\text { Natural } \\
\text { Scientist }\end{array}$ \\
\hline Dream Reports & 208 & 312 & 234 \\
Characters & 381 & 1,127 & 356 \\
Edges & 767 & 5,482 & 689 \\
Average Shortest Path Length & & & \\
$\quad$ Dream social network & 2.75 & 2.82 & 3.95 \\
$\quad$ Random affiliation networks & 2.55 & 2.07 & 2.98 \\
$\quad$ Clustering Coefficient & & & \\
$\quad$ Dream social network & .73 & .91 & .62 \\
$\quad$ Random affiliation networks & .24 & .14 & .62 \\
$\quad$ Power Law* & & & \\
$\quad$ Parameter $a$ & 1.29 & 1.43 & 0.63 \\
$\quad r^{2}$ & .84 & .85 & .82 \\
\hline
\end{tabular}

*With power law distribution, truncated to median and above, the probability of degree $k$ is $1 /[\zeta(a+1)-\zeta(m-1)] k^{a+1} ; \xi$ denotes the Riemann zeta function, and $m$, the median degree. Parameter $a$ is estimated by least squares. characters in dreams and the number of dreams per character are drawn from their respective observed distributions, but characters are assigned to dreams at random. Two characters are joined by an edge if they are in the same dream.

Results for this population of random affiliation networks are in Table 1. As can be seen in the table, average observed shortest path lengths are near those for the comparable random affiliation networks. It is informative whether the clustering coefficient is considerably higher than that for comparable random affiliation networks. That is the case for Arlie and Merri.

The network for The Natural Scientist is different. The clustering coefficient for his network is equal (within rounding) to that predicted for comparable random affiliation networks. Granted, the latter is already quite high, but it can be exceeded, as the examples of Arlie and Merri show. Results like the following keep The Natural Scientist's clustering from being higher: His sister Faye is in a dream with her husband, and her husband is in a dream with his and Faye's son, but Faye is not in a dream with their son.

The third property of interest is a power-law degree distribution. A more familiar formulation is Zipf's law (Zipf, 1945), which says that if observed degrees are ranked, $\log$ degree is a linear function of log rank. A power law leads to Zipf's law being approximately true (Johnson et al., 1992). Figure 3 plots the natural $\log$ of each degree against the natural $\log$ of the rank of that degree $(\log 0$, undefined, is omitted).

The relation is nonlinear for low log degree (where degree is low). Most characters of low degree appear in only one 

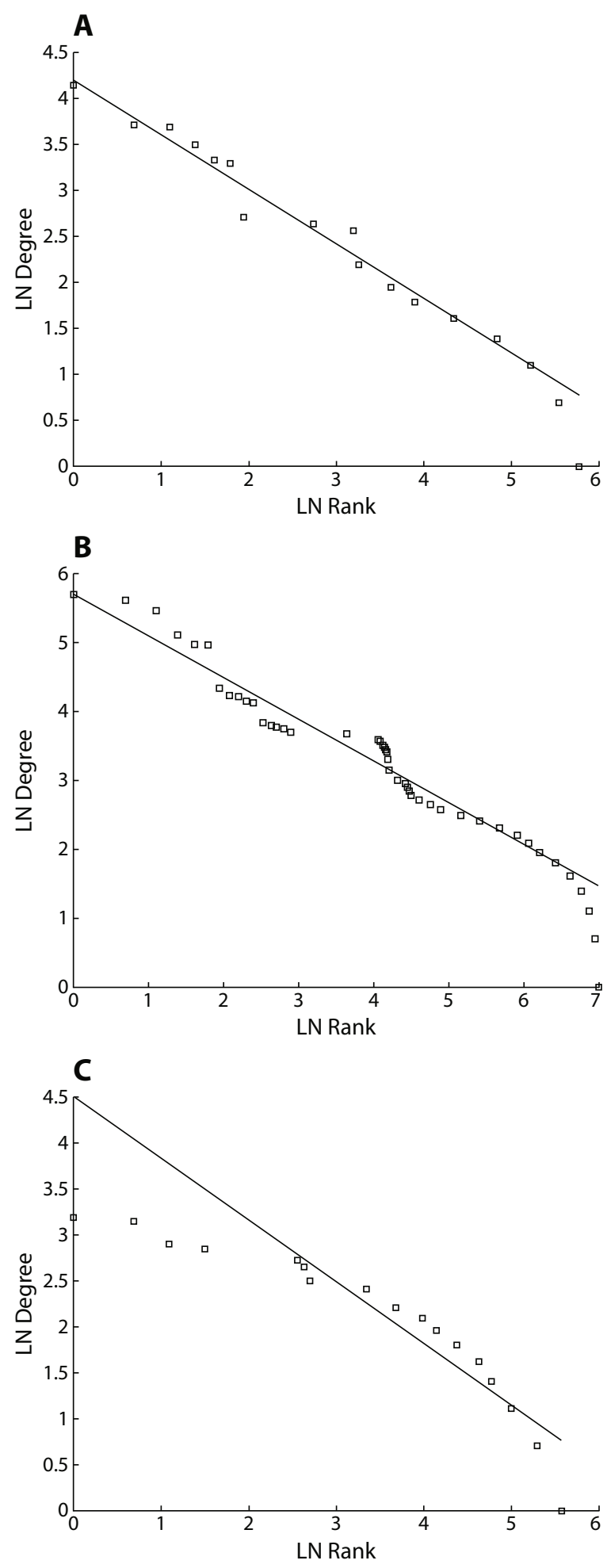

Figure 3. Zipf's law. Best-fitting line for median degree and above. (A) Arlie. (B) Merri. (C) The Natural Scientist.

dream, so the bulk of the low-degree distribution reflects the distribution of the number of characters in a dream. Illustrated for each dreamer is the best fitting straight line for log degree at or above the log of the median degree, the median degree being the highest degree that at least half the characters have, at a minimum, attained. Medians are 3, 6, and 2 for Arlie, Merri, and The Natural Scientist, respectively. There is a good fit for Zipf's law in this range, although for The Natural Scientist a better line would result if more low degrees were omitted. More characters have low degrees than have high, so the fits are weighted toward low degrees.

To examine the power law directly, a power law was fit to the empirical probability distributions of degrees at or above the medians. Good values of $r^{2}$ indicate that a power law fits well in this range, although somewhat less well for The Natural Scientist (Table 1).

Whether or not the originating signals for dreams are more or less random, as proposed by Hobson and McCarley (1977), the end products are nonrandom for Arlie and Merri, because their clustering coefficients are higher than comparable random affiliation networks predict. Further evidence against characters occurring together at random for Arlie and Merri is in Table 2, presenting frequencies of occurrences and co-occurrences for their four highest degree characters. For Arlie, co-occurrence frequencies predicted by independence are small, so a statistical test is not feasible. By inspection, the dreamer's mother and father occur together much more than predicted by statistical independence. For Merri, chi-square tests $(1 d f)$ indicate that major characters do not co-occur at random - that is, independently - except for her sister and brother. Instead, characters are generated in accordance with the dreamer's knowledge of social relations. For The Natural Scientist, frequencies are too small to draw conclusions, but it is noteworthy that some high frequency characters do not occur in a dream together.

To summarize, two forms of social networks of characters in dreams were found. All have average shortest path lengths near those of comparable random affiliation networks. Clustering is higher than that for comparable random affiliation networks for two individuals, but equal for one individual. That individual has a treelike structure; the first two individuals have small world structures. If .62 can be considered high clustering, the third individual also has small world structure. For all, a power law degree distribution fits well when low degrees are omitted.

\section{DISCUSSION}

One can only speculate about why the network of The Natural Scientist is treelike. A larger sample of dream reports might lead to different results, of course. Perhaps in waking life, his family does not know his friends, and so on, and his dream network represents this. But this does not explain why his sister is not in a dream with her son. Perhaps his cognitive style is to focus; he is a taxonomist by profession (Domhoff, 1996), and his dreams reflect this. For more about him, see Hobson (1988) and Domhoff (1996), who call him The Engine Man.

Organization in dreams arises largely from the dreamer's associative memory, so some portion of the dream social network exists in the memory of the dreamer. Although it is impossible to know what portion exists, results here support the validity of a hypothesis of Tsonis and 
Table 2

Contingency Analyses for Most Frequent Characters

\begin{tabular}{|c|c|c|c|c|}
\hline & \multicolumn{4}{|c|}{ Independence } \\
\hline & Frequencies & Prediction & $\chi^{2}$ & $p$ \\
\hline \multicolumn{5}{|l|}{ Arlie } \\
\hline Husband & 29 & & & \\
\hline Younger son & 21 & & & \\
\hline Mother & 18 & & & \\
\hline Father & 14 & & & \\
\hline Husband and younger son & 6 & 2.93 & & \\
\hline Husband and mother & 3 & 2.51 & & \\
\hline Husband and father & 2 & 1.95 & & \\
\hline Younger son and mother & 2 & 1.82 & & \\
\hline Younger son and father & 1 & 1.41 & & \\
\hline Mother and father & 11 & 1.21 & & \\
\hline \multicolumn{5}{|l|}{ Merri } \\
\hline Sister & 68 & & & \\
\hline Brother & 63 & & & \\
\hline Mother & 57 & & & \\
\hline Father & 40 & & & \\
\hline Sister and brother & 17 & 13.73 & 1.25 & n.s. \\
\hline Sister and mother & 22 & 12.42 & 11.55 & $<.001$ \\
\hline Sister and father & 14 & 8.72 & 4.69 & $<.05$ \\
\hline Brother and mother & 17 & 11.51 & 4.02 & $<.05$ \\
\hline Brother and father & 15 & 8.08 & 8.53 & $<.01$ \\
\hline Mother and father & 17 & 7.31 & 18.04 & $<.001$ \\
\hline \multicolumn{5}{|l|}{ The Natural Scientist } \\
\hline Mother & 12 & & & \\
\hline Anderson (friend) & 8 & & & \\
\hline Chester (friend) & 9 & & & \\
\hline Faye (sister) & 9 & & & \\
\hline Mother and Anderson & 2 & 0.41 & & \\
\hline Mother and Chester & 0 & 0.46 & & \\
\hline Mother and Faye & 3 & 0.46 & & \\
\hline Anderson and Chester & 2 & 0.31 & & \\
\hline Anderson and Faye & 1 & 0.31 & & \\
\hline Chester and Faye & 0 & 0.35 & & \\
\hline
\end{tabular}

Tsonis (2004): that associations in memory have small world structure. During dreaming, an elaborate narrative is constructed, and an intriguing question is whether new associations are formed and remain in memory, even if the dream is not recalled.

Dreams are somewhat random in appearance, and dream social networks are similar to some random networks in having short paths. Short paths may make dreams a source of creative combinations of ideas (Barrett, 2001; Schilling, 2005). But random combinations of ideas are rarely useful, and, contrary to another hypothesis of Tsonis and Tsonis (2004), dream networks are not actually random.

Dream reports are a potentially valuable source of information about social networks. Recall of dreams is not always accurate, so dream reports cannot eliminate the problem of fallible memory for social contacts. But social network researchers often want information about the people important to an individual (Wasserman \& Faust, 1994), and dream reports provide this. A clear example is in Merri's dream reports. Her deceased sister is no longer in her waking social network, but is the person she most often dreams about.

\section{AUTHOR NOTE}

I thank G. William Domhoff, Reeshad Dalal, Ehtibar Dzhafarov, and Mark Steyvers for help, and Daniel Poyter, Mona Reed, Lisa Siqueira, and Reuben Ternes for useful discussions of coding. Correspondence concerning this article should be addressed to R. Schweickert, Department of Psychological Sciences, Purdue University, West Lafayette, IN 47907 (e-mail: swike@psych.purdue.edu).

\section{REFERENCES}

Albert, R., Jeong, H., \& Barabasi, A. L. (1999). Diameter of the World Wide Web. Nature, 401, 130-131.

Arkin, A. M., \& ANTrobus, J. S. (1991). The effects of external stimuli applied prior to and during sleep on sleep experience. In S. J. Ellman \& J. S. Antrobus (Eds.), The mind in sleep: Psychology and psychophysiology (2nd ed., pp. 265-307). New York: Wiley.

BARABASI, A. L., \& ALBERT, R. (1999). Emergence of scaling in random networks. Science, 286, 509-512.

BARRETT, D. (2001). The committee of sleep. New York: Crown.

Batagel, V., \& MrVar, A. (1998). Pajek-Program for large network analysis. Connections, 21, 47-57.

Bearman, P. S., Moody, J., \& Stovel, K. (2004). Chains of affection: The structure of adolescent romantic and sexual networks. American Journal of Sociology, 110, 44-91.

Braun, A. R., Balkin, T. J., Wesensten, N. J., Gwadry, F., Carson, R. E., VARGA, M., ET AL. (1998). Dissociated pattern of activity in visual cortices and their projections during human rapid eye movement sleep. Science, 279, 91-95.

BREWER, D. D. (2000). Forgetting in the recall-based elicitation of personal and social networks. Social Networks, 22, 29-43.

Collins, A. M., \& LofTus, E. F. (1975). A spreading-activation theory of semantic processing. Psychological Review, 82, 407-428.

Domнoff, G. W. (1996). Finding meaning in dreams: A quantitative approach. New York: Plenum.

Domнoff, G. W. (2003). The scientific study of dreams: Neural net- 
works, cognitive development, and content analysis. Washington, DC: American Psychological Association.

Fosse, M. J., Fosse, R., Hobson, J. A., \& Stickgold, R. J. (2003). Dreaming and episodic memory: A functional dissociation? Journal of Cognitive Neuroscience, 15, 1-9.

Foulkes, D. (1985). Dreaming: A cognitive-psychological analysis. Hillsdale, NJ: Erlbaum.

Grenier, J., Cappeliez, P., St-Onge, M., Vachon, J., Vinette, S., Roussy, F., ET AL. (2005). Temporal references in dreams and autobiographical memory. Memory \& Cognition, 33, 280-288.

Hall, C. S., \& Nordby, V. J. (1972). The individual and his dreams. New York: New American Library.

Hall, C. S., \& VAN DE CASTle, R. L. (1966). The content analysis of dreams. New York: Appleton-Century-Crofts.

Hobson, J. A. (1988). The dreaming brain. New York: Basic Books.

Hobson, J. A., \& McCARley, R. W. (1977). The brain as a dream state generator: An activation-synthesis hypothesis of the dream process. American Journal of Psychiatry, 134, 1335-1348.

Johnson, N. L., Kotz, S., \& KemP, A. W. (1992). Univariate discrete distributions (2nd ed.). New York: Wiley.

Killworth, P. D., \& Bernard, H. R. (1976). Informant accuracy in social network data. Human Organization, 35, 269-286.

Kumbasar, E., Romney, A. K., \& Batchelder, W. H. (1994). Systematic biases in social perceptions. American Journal of Sociology, 100, 477-505

McNamara, P., Mclaren, D., Smith, D., Brown, A., \& Stickgold, R. (2005). A "Jekyll and Hyde" within: Aggressive versus friendly interactions in REM and non-REM dreams. Psychological Science, 16, 130-136.

Milgram, S. (1967). The small world problem. Psychology Today, 1, 60-67.

Miller, G. A. (1990). WordNet: An on-line lexical database [Special issue]. International Journal of Lexicography, 3(4).

Nelson, D. L., McEvoy, C. L., \& Schreiber, T. A. (1999). The University of South Florida word association, rhyme, and word fragment norms. Retrieved from w3.usf.edu/FreeAssociation/.

Newman, M. E. J. (2003). The structure and function of complex networks. SIAM Review, 45, 167-256.

Newman, M. E. J., Watts, D. J., \& Strogatz, S. H. (2002). Random graph models of social networks. Proceedings of the National Academy of Sciences, 99, 2566-2572.

Nusbaum, H. C., Pisoni, D. B., \& Davis, C. K. (1984). Sizing up the Hoosier Mental Lexicon: Measuring the familiarity of 20,000 words. In Research on speech perception (Progress Report No. 10). Bloomington: Indiana University Press.

Roget, P. M. (1911). Roget's Thesaurus of English words and phrases (1911 ed.). Retrieved October 28, 2004, from www.gutenberg.org/ etext/10681.

Rumelhart, D. E., Lindsay, P., \& Norman, D. A. (1972). A process model for long-term memory. In E. Tulving \& W. Donaldson (Eds.), Organization of memory (pp. 197-246). New York: Academic Press.

Schilling, M. A. (2005). A "small-world" network model of cognitive insight. Creativity Research Journal, 17, 131-154.

SchneIDER, A., \& Domhoff, G. W. (2005). DreamBank. Retrieved June 20, 2005, from www.dreambank.net/.

SCHWEICKERT, R. (2007). The structure of semantic and phonological networks and the structure of a social network in dreams. In J. S. Nairne (Ed.), The foundations of remembering: Essays in honor of Henry L. Roediger III (pp. 283-298). Hove, U.K.: Psychology Press.

Sporns, O., Tononi, G., \& Edelman, G. M. (2000). Theoretical neuroanatomy: Relating anatomical and functional connectivity in graphs and cortical connection matrices. Cerebral Cortex, 10, 127-141.

Stephan, K. E., Hilgetag, C. C., Burns, G. A. P. C., O’Neill, M. A., Young, M. P., \& KotTer, R. (2000). Computational analysis of functional connectivity between areas of primate cerebral cortex. Philosophical Transactions of the Royal Society of London: Series B, 355, 111-126.

Steyvers, M., \& Tenenbaum, J. B. (2005). The large-scale structure of semantic networks: Statistical analysis and a model of semantic growth. Cognitive Science, 29, 41-78.

Tsonis, P. A., \& Tsonis, A. A. (2004). A "small-world" network hypothesis for memory and dreams. Perspectives in Biology \& Medicine, 47, 176-180.

ViteVitch, M. S. (2005). Phonological neighbors in a small world: What can graph theory tell us about word learning? Unpublished manuscript, Department of Psychology, University of Kansas.

Wasserman, S., \& Faust, K. (1994). Social network analysis: Methods and applications. Cambridge: Cambridge University Press.

Watts, D. J., \& Strogatz, S. H. (1998). Collective dynamics of "smallworld" networks. Nature, 393, 440-442.

ZIPF, G. K. (1945). The meaning-frequency relationship of words. Journal of General Psychology, 33, 251-256.

(Manuscript received January 26, 2006; revision accepted for publication May 17, 2006.) 